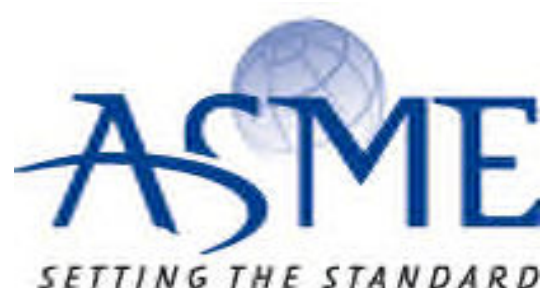

SETTING THE STANDARD

\section{American Society of \\ Mechanical Engineers}

ASME Accepted Manuscript Repository

Institutional Repository Cover Sheet

Cranfield Collection of E-Research - CERES

ASME Paper Tile: Assessment of thermo-electric power plants for rotorcraft application

Ioannis Roumeliotis, Christos Mourouzidis, Mirko Zafferetti, Deniz Unlu, Olivier Broca, and

Authors: Vassilios Pachidis

ASME Journal Title: Journal of Engineering for Gas Turbines and Power

ASME Digital Collection https://asmedigitalcollection.asme.org/gasturbinespower/article/142/5/051003/106541 URL:

DOI: 


\title{
Assessment of Thermo-Electric Power Plants for Rotorcraft Application
}

\author{
Ioannis Roumeliotis ${ }^{1}$ \\ Lecturer \\ Centre for Propulsion Engineering, \\ Cranfield University, \\ Bedfordshire MK43 OAL, UK \\ e-mail: i.roumeliotis@cranfield.ac.uk

\section{Christos Mourouzidis} \\ Research Fellow \\ Centre for Propulsion Engineering, \\ Cranfield University, \\ Bedfordshire MK43 OAL, UK \\ e-mail: c.mourouzidis@cranfield.ac.uk

\section{Mirko Zafferetti} \\ Centre for Propulsion Engineering, \\ Cranfield University, \\ Bedfordshire MK43 0AL, UK \\ e-mail:m394z2008@gmail.com

\section{Unlu Deniz} \\ Siemens Industry Software SAS \\ La Cité Internationale \\ 84, quai Charles de Gaulle \\ 69006 Lyon, France \\ e-mail: deniz.unlu@siemens.com

\section{Olivier Broca} \\ Siemens Industry Software SAS \\ La Cité Internationale \\ 84, quai Charles de Gaulle \\ 69006 Lyon, France \\ e-mail: olivier.broca@siemens.com
}

\section{Vassilios Pachidis}

Professor

Centre for Propulsion Engineering,

\footnotetext{
${ }^{1}$ Corresponding author
} 
Cranfield University, Bedfordshire MK43 OAL, UK

e-mail: v.pachidis@cranfield.ac.uk

\section{ABSTRACT}

This paper assesses a parallel electric hybrid propulsion system utilizing simple and recuperated cycle gas turbine configurations. An adapted engine model capable to reproduce a turboshaft engine steady state and transient operation is built in Simcenter Amesim and used as a baseline for a recuperated engine. The transient operation of the recuperated engine is assessed for different values of heat exchanger effectiveness, quantifying the engine lag and the surge margin reduction which are results of the heat exchanger addition. An oil and gas mission of a twin engine medium helicopter has been used for assessing the parallel hybrid configuration. The thermo-electric system brings a certain level of flexibility allowing for better engine utilization, thus firstly a hybrid configuration based on simple cycle gas turbine scaled down from the baseline engine is assessed in terms of performance and weight. Following the recuperated engine thermo-electric power plant is assessed and the performance enhancement is compared against the simple cycle conventional and hybrid configurations. The results indicate that a recuperated gas turbine based thermo - electric power plant may provide significant fuel economy despite the increased weight. At the same time, the electric power train can be used to compensate for the reduced specific power and potentially for the throttle response change due to the heat exchanger addition.

\section{INTRODUCTION}

The aviation industry is recognized as the most rapidly growing source of $\mathrm{CO} 2$ emissions given that the 2035 global traffic is fore-casted to be twofold the one in 2016 [1]. Rotorcrafts are going to be part of this growth since helicopters are seen as a quick and safe way to transport patients between hospitals [2]. Additionally the traffic for passenger transport/air taxi, which has been a marginal activity until now, is expected to boom in the near future with a forecasted two to three-fold increase in the $2015-2020$ period [3]. Therefore, the rotorcraft fleet contribution to environmental impact is becoming a concern and measures to reduce it are investigated and assessed. The Advisory Council for Aeronautics Research in Europe (ACARE) has established specific environmental goals to be met by the civil aviation industry (including rotorcraft and aircraft) by the year 2020 in order to sustain aviation's present environmental impact after the expected aircraft and rotorcraft fleet growth [4]. 
The development of new technologies can potentially hinder the environmental emissions of the aviation industry. Several ways to tackle this challenge have been proposed ranging from changing the aircraft operational procedures [4] to system architecture ([5], [6]). The "More Electric Aircraft" (MEA) concept is expected to be in the forefront of this change, given that already pneumatic and hydraulic aircraft systems are replaced by electric systems [7]. On longer term hybrid electric and universally electric aircraft are considered as promising concepts for addressing the NASA N+3 [8] goals and the Strategic Research Innovation Agenda as discussed by Vratny et al. [9].

Thermo-electric configurations bring a certain level of flexibility into the powerplant design and the vehicle as a whole, since the engine may operate in more favourable operating points throughout the mission, providing propulsive power and electric power in several systems at the same time. This flexibility is of interest for rotorcrafts since typical helicopter cruises between $55 \%$ to $65 \%$ of the maximum continuous power for around $80 \%$ to $90 \%$ of the helicopter flight [10], meaning that they operate at high specific fuel consumption (sfc). Another interesting aspect is that in the case of hybrid propulsion the OEI (One Engine Inoperative) ${ }^{1}$ rating can be achieved by utilizing the battery pack adding to the safety and reducing the need for engine oversizing.

Especially for rotorcrafts, hybrid electric configurations may offer high reliability and lower maintenance cost, mainly due to reducing the gearboxes and transmissions, components that do not have graceful failure modes. These advantages come with increased weight and complexity of the whole propulsion system, thus for assessing the performance of a hybrid propulsion system the increased weight of the helicopter should be considered.

Another way to address the increased specific fuel consumption during part-load operation of helicopters is the recuperated cycle. The deployment of regenerative technology for enhancing the operational capabilities of helicopters, specifically for

\footnotetext{
1 The One-Engine-Inoperative (OEI) rating powers provide rotorcraft with higher than takeoff and maximum continuous rating powers during takeoff, cruise, and landing when one or more engines of a multi-engine rotorcraft fails or is shutdown.
} 
military use, has been of interest since 1960s [11]. Despite the well established benefits in terms of fuel consumption that can accrue from recuperation reliability concerns and the insignificant operating cost savings in an era of low-fuel cost; made this technology less attractive since there was still room for significant improvement of the simple cycle [12]. Through the continuous advancement of gas turbines the simple cycle configuration approached its performance limits and new aircraft designs integrating heat exchangers has been proposed (e.g. [13]). This development reignited interest in recuperated turboshaft engines as well. Fakhre et al. [14] demonstrated that the conceptual recuperated helicopter has the potential to significantly improve the maximum attainable range capability, achieving a significant reduction in mission fuel burn but may cause an increase in NOx emissions.

The advantages of the recuperated cycle come with increased weight, complexity and lower specific power due to the heat exchanger pressure losses. The latter is important if an existing engine is considered for modification, since its power ratings are expected to significantly decrease, thus it may not be capable to power existing helicopters, as discussed by Roumeliotis et al. [15]. Additionally the dynamic behaviour of the engine is expected to change due to the thermal inertia of the heat exchanger changing the throttle response of the system [16]. Despite the fact that recuperated configurations have been proposed for rotorcraft propulsion, recuperated cycles as part of a thermo-electric power plant have not be assessed in the literature. A thermo-electric powerplant utilizing a recuperated cycle can address the negative effect of heat exchanger pressure losses to the engine power output, since the electrical power train can provide the power boost needed at specific mission segment, making this concept more interesting. In this case existing engines can be modified decreasing the development time and cost. Additionally a hybrid - electric configuration can compensate for the thermal inertia effect during acceleration by utilizing the electric power system since electric motors can produce their torque within a few milliseconds [17].The aim of this work is to give a deeper insight in the performance and operability characteristics of thermo-electric power plant based on recuperated gas turbine for 
helicopter applications. A parallel hybrid configuration is selected since no distributed propulsion is considered, thus eliminating the need for adding the weight of a generator ([15], [18]).

For assessing the hybrid configurations for rotorcraft propulsion relevant dynamic models are built in Simcenter Amesim. A simple cycle engine adapted on publicly available experimental data of a T700-GE-700 is used as the baseline. Following a recuperated version of the engine is developed and its performance is assessed for different values of heat exchanger effectiveness. The transient operation of the recuperated engine is also simulated for assessing its operability and reaction time. Having established a recuperated version of the engine an integrated parallel hybrid configuration utilizing both the simple cycle and the recuperated configuration models is built in Simcenter Amesim, allowing for the dynamic simulation and performance assessment of both the turboshaft engine and the electric power train at the same time. Firstly the performance and weight of simple cycle gas turbine based configurations are assessed. The engines are scaled down versions of the baseline engine. Then the configurations utilizing the recuperated engines are assessed and their weight and performance are calculated. The different configurations are compared and the benefits accrued from utilizing hybrid propulsion based on recuperated gas turbine are assessed and discussed.

\section{SIMCENTER AMESIM GAS TURBINE LIBRARY}

The Simcenter Amesim Gas Turbine library consists of components such as compressor, turbine, combustor, ducts etc. The modular nature of a gas turbine engine makes the identification of components and connections a straight forward procedure. In addition to the usual components, volume components can be used for taking into account the volume dynamics effect on engine transient operation and variable orifices to simulate bleed off valves (BOV). Components from other libraries such as shafts for accounting for shaft dynamics, propellers, gearboxes, generators, heat exchangers, pumps can be combined with the gas turbine library components to allow the modelling of any gas turbine configuration and of integrated systems as well. 
The compressor and turbine modelling is based on the well established rigorous entropy calculations described by Walsh and Fletcher [20] and Kurzke [21]. The variable geometry effect on turbomachinery map is simulated by applying the methodology described by Kurzke [21]. Compressor and turbine maps correction for accounting working medium composition (e.g. humidity for compressor and fuel synthesis for turbine) is done utilizing the method suggested in AGARD AR-332 [22]. This feature can be activated / deactivated. For simulating turbomachinery components degradation the health indices concept as introduced by Stamatis et al. [23] has been implemented. Suitable health indices can be used for simulating specific components faults [24].

The volume dynamics and the heat transfer between the gas and the surrounding parts of the engine are represented by the chamber component with heat exchanges. The heat flow can be modelled utilizing the Simcenter Amesim thermal library components and the relevant materials library. The ducts are modelled as orifices of specific flow coefficient, where the flow coefficient can be calculated via available geometrical data or imposed by the user. This approach allows for varying pressure losses throughout operation, as a function of corrected mass flow. The combustion is modelled utilizing chemical kinetics and the relevant reaction rate coefficient [25]. Any fuel composition can be applied and the combustion products are calculated based on the stoichiometric equation. The combustion chamber components available are: the primary zone accounting for the formation of the flame kernel, combustion and pressure drop and the secondary zone accounting for further chemical reactions and pressure drop. Both components can account for heat transfer applying thermal library components, while cooling holes can be considered too. The secondary zone can be further discretized utilizing several secondary zone components for representing the dilution zone. The fluid properties are calculated according to the NASA CEA data [26].

The ambient air synthesis can be defined by the user in molar or mass basis. The ambient air conditions can be defined by the user or calculated via the atmosphere component. International standard atmosphere (ISA) [27], U.S. standard atmosphere 1976 [28] and Military standard atmosphere models [29], [30] are available for 
selection. The ISA non-standard days are also available (hot, cold, tropical and polar) for assessing the system operation in the extremes of the design envelope.

By using the gas turbine library any engine model can be built. The modular nature of the gas turbine engine makes this a straight forward process. In order to relate flow quantities at the inlet and outlet of individual engine components, the equations of mass and energy conservation along with species concentration conservation are employed, while shaft components impose torque calculations. The equations are solved through a well established integrator switching automatically between several algorithms depending on the numerical stiffness of the system [31], [32], [33].

The gas turbine library set of components can be combined with a plethora of components of other libraries such as electrical, control and thermal, allowing the modelling of conventional and unconventional engines, the analysis of integrated systems and the application of different control strategies. For streamlining the engine model building process a compressor and turbine map scaling tool is available. The engine design point can be derived from the open literature [34], measurement data [35] or design calculations based on technology level [36]. The map scaling tool (Figure 1) allows for the point and click selection of the initial map design point, hence the map scaling factors [37] can be directly calculated.

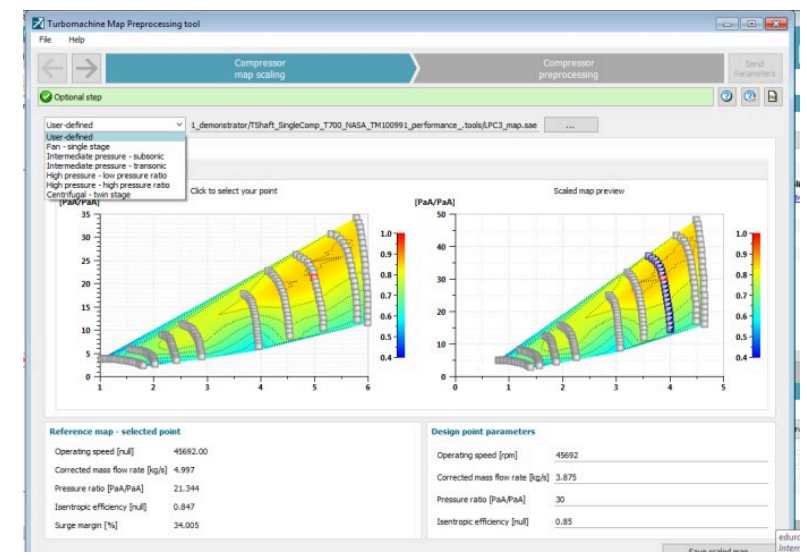

Figure 1: Simcenter Amesim compressor map scalling tool 


\section{TEST CASE ENGINES}

A simple cycle and a recuperated engine are used herein as test case engines. The simple cycle engine is based on the T700-GE-700, a turboshaft engine broadly used in Twin Engine Medium (TEM) helicopters. A model adapted to available experimental measurements [19] is built and assessed. Then the simple cycle engine is acting as the baseline for a recuperated engine.

\section{Simple Cycle Engine}

The T700-GE-700 is the first production model of the T700 family (first engine delivered in early 1978) [38]. It consists of a five-stage axial and a single-stage centrifugal flow compressor; a low-fuel-pressure, annular combustion chamber; a twostage axial flow gas generator turbine; and a two-stage uncooled independent power turbine [38]. The engine model built can be seen in Figure 2, utilizing fuel flow as the setting parameter and applying the maximum allowable turbine inlet temperature (T41), as defined at stator exit, as limiter.

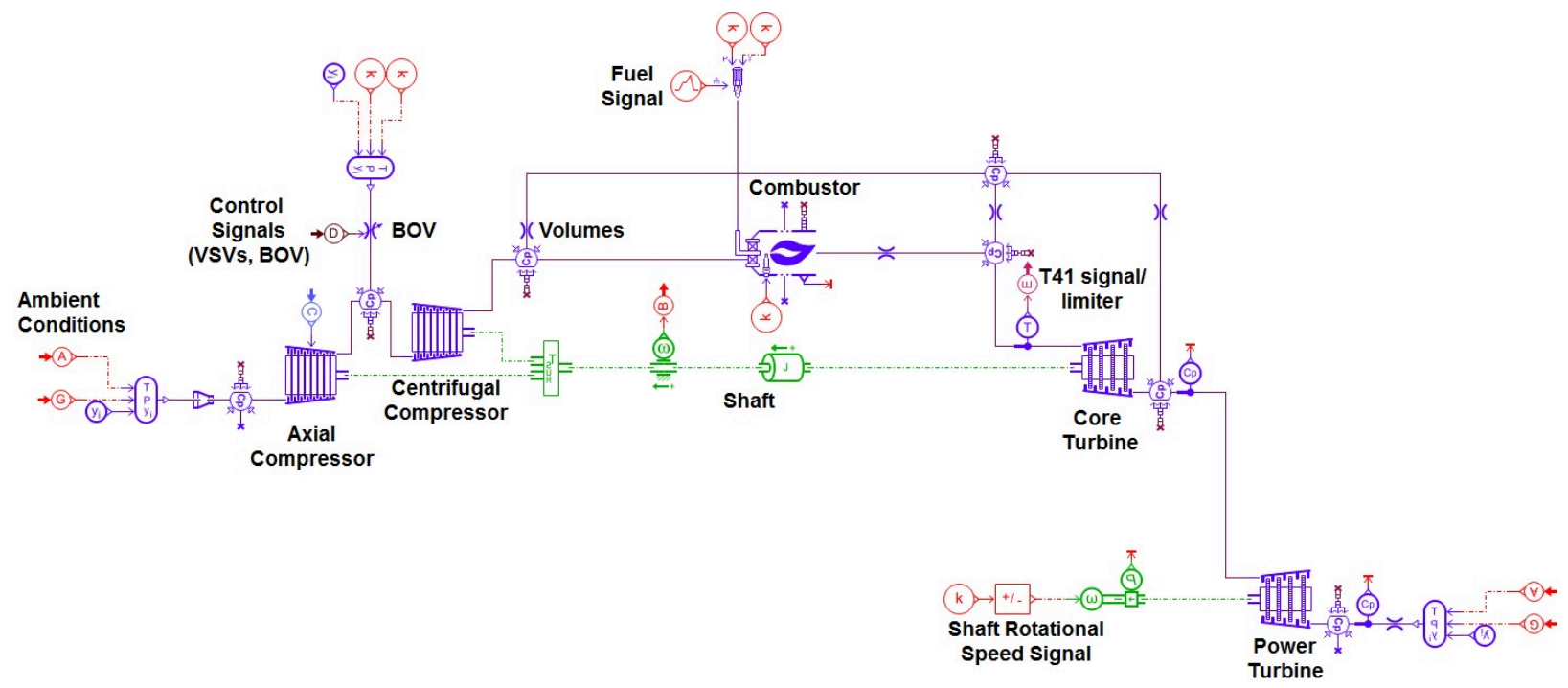

Figure 2: Simcenter Amesim engine model

The gas generator consists of a five stage axial compressor (LPC), a single centrifugal stage (HPC) driven by a two stage cooled axial turbine (CT) and a two stage free power turbine (PT) delivering shaft power. The model utilizes the Simcenter Amesim readily available maps to define off-design performance for the turbomachinery 
components. The combustor pressure losses vary with the combustor inlet corrected mass flow rate. Ducts pressure losses are a function of mass flow rate. Cooling flows for the CT are extracted from the HPC exit, assuming a bleed percentage of $10 \%$ relative to the inlet flow, following the cooling flow data presented by Ballin [19]. The cooling flow split is selected following the equivalent single stage cooled turbine logic [20], [39]. The work potential of the cooling flow is defined equal to 0.6 based on the value suggested by Kurzke [39] for two stage cooled turbines.

For ensuring low power stable operation the first and second stator vanes of the axial compressor are of variable geometry (VGVs) and starting air is bled off from the axial compressor exit through a bleed off valve (BOV). Both VGVs and BOV position is a function of ambient temperature and rotational speed and they are activated when the corrected gas generator speed is less than $87 \%$ of the nominal one. The VGVs are modelled utilizing the relevant mass flow correction as a function of angle [21], assuming no penalty on efficiency and pressure ratio according to the measurement data discussed in [35]. The BOV is modelled through a variable area orifice component. Kerosene $(\mathrm{C} 10 \mathrm{H} 20)$ is used as fuel in this study.

The model is adapted to the experimental data presented by Ballin [19] and depicted in Table 1. The operating point for scaling the model and maps is selected the one with the maximum torque. Following a model adaptation to the engine available data utilizing components modification factors [35] was performed. As seen in Figure 3 the adapted engine model reproduces the engine steady state experimental data with very good accuracy throughout the whole operating envelope.

Table 1: Experimental data from NASA-Lewis experimental test engine [19]

\begin{tabular}{|r|r|r|r|r|r|r|}
\hline $\begin{array}{c}\text { T2 } \\
{[\mathrm{C}]}\end{array}$ & $\begin{array}{c}\text { NGG } \\
{[\%]}\end{array}$ & $\begin{array}{c}\mathrm{Np} \\
{[\%]}\end{array}$ & $\begin{array}{c}\mathrm{W} 2 \\
{[\mathrm{~kg} / \mathrm{s}]}\end{array}$ & $\begin{array}{c}\mathrm{p} 3 \\
{[\mathrm{bar}]}\end{array}$ & \multicolumn{1}{c|}{$\begin{array}{c}\mathrm{T} 3 \\
{[\mathrm{C}]}\end{array}$} & $\begin{array}{c}\text { Torque } \\
{[\mathrm{Nm}]}\end{array}$ \\
\hline 13.9 & 65.9 & 52.6 & 1.45 & 4.0 & 189.1 & 40.8 \\
\hline 13.3 & 84.7 & 95.7 & 2.34 & 7.8 & 296.9 & 122.2 \\
\hline 9.2 & 87.7 & 95.7 & 2.79 & 9.6 & 327.4 & 201.1 \\
\hline 9.1 & 90.4 & 95.7 & 3.13 & 11.1 & 353.0 & 280.0 \\
\hline 8.6 & 92.6 & 95.7 & 3.47 & 12.7 & 378.5 & 371.9 \\
\hline 8.6 & 95.9 & 95.7 & 3.86 & 14.6 & 409.1 & 489.2 \\
\hline
\end{tabular}

The model deviates from the experimental data when operation close to idle is considered. This is expected since there are no public domain data available for the 
engine component characteristics on the idle operating regime. The turbomachinery component low rotation speed isolines, VGVs and BOV schedules, to name some parameters, are of high importance when operation close to idle is considered. In this case, generic component maps and schedules are used.

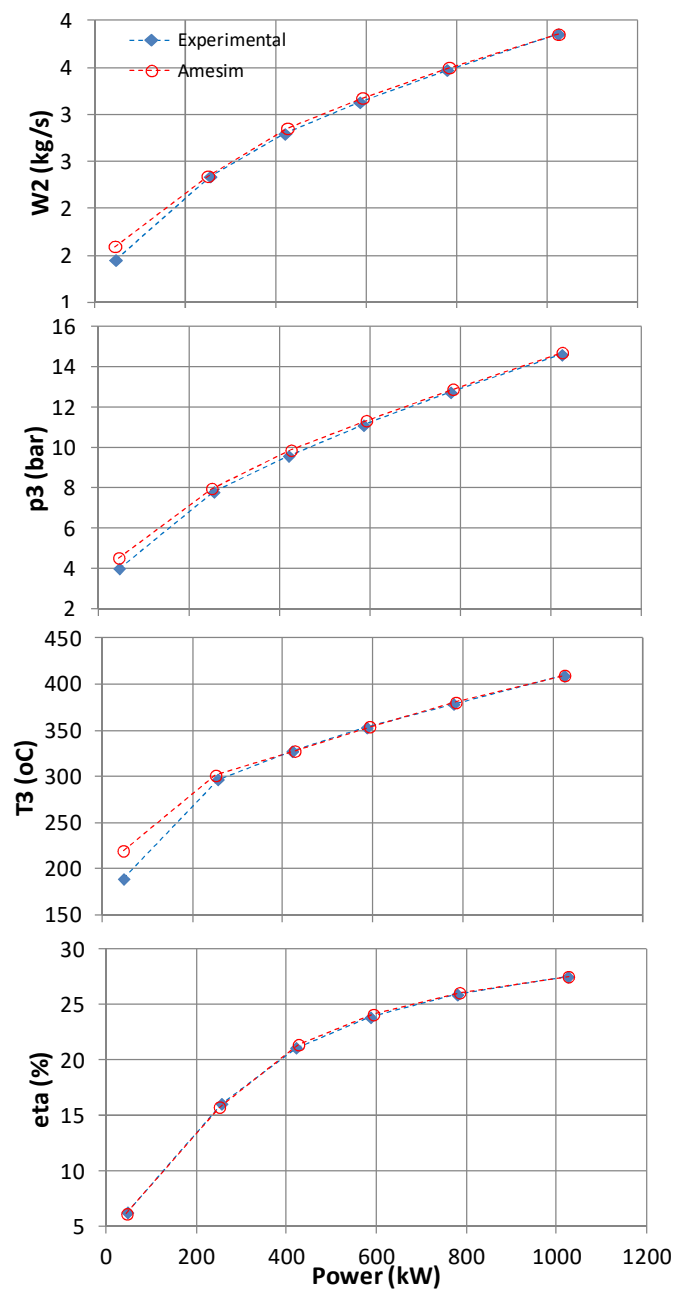

Figure 3: Measured [19] versus calculated data for steady state operation

Simcenter Amesim is a dynamic simulation environment; hence the model built for steady state simulation can be directly used for transient simulation. Shaft inertia is the dominant term [40]. The gas generator and power turbine shaft moment of inertias are defined equal to $0.06033 \mathrm{~kg} \cdot \mathrm{m}^{2}$ and $0.084 \mathrm{~kg} \cdot \mathrm{m}^{2}$ following the values recommended by Ballin [19]. The gas dynamic effects are considered utilizing the volume components. For this size of engine the gas dynamics effects are expected to be small [41]. The heat soakage effect is expected to be small according to the results presented by Ballin [19] 
and it is not considered in this model. The heat soakage effect can be easily applied utilizing components from the thermal and material libraries.

The transient behaviour of the model for the case of a fuel step increase can be seen in Figure 4. The gas generator speed, compressor discharge pressure and torque variation are presented along with calculated data presented by Ballin [19].

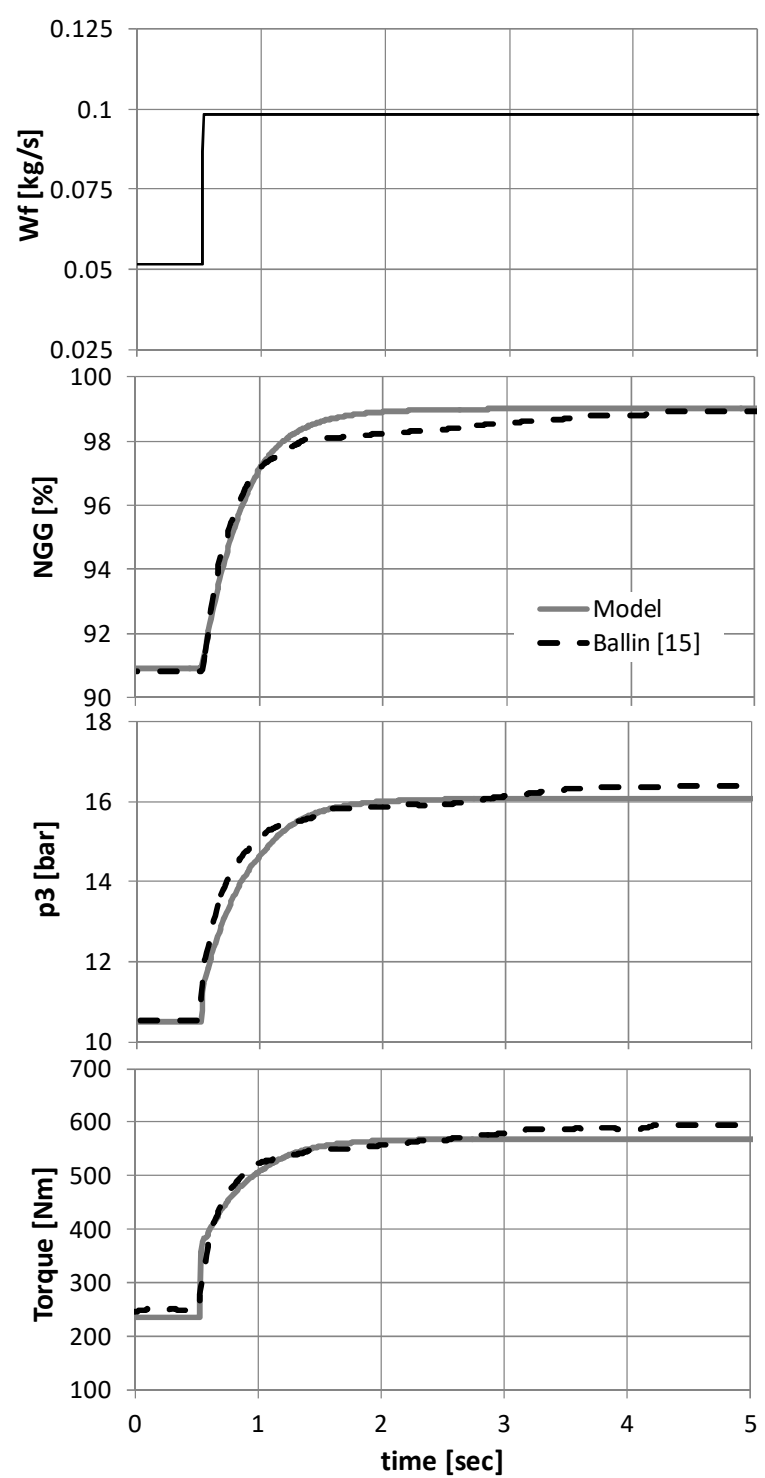

Figure 4: Simulated in [19] versus Simcenter Amesim calculated data for a fuel step increase

As seen the model built in Simcenter Amesim and adapted to the relevant steady state data presents the expected behaviour in terms of time constants and values for transient operation as well, thus it can be used for assessing both the steady state and transient operation of the engine. 


\section{Recuperated Engine}

In this study the test case engine is acting as the baseline for the recuperated engine. Recuperated engines have been considered for rotorcraft configurations (e.g. [12], [14]) and assessed from a performance point of view. The simple cycle engine model built is easily changed to a recuperated cycle utilizing the relevant available heat exchanger components. Simcenter Amesim offers several levels of detail for modelling the heat exchanger. The simplest model is selected, applying off design change of effectiveness based on eq. (1) [20]:

$$
\text { eff }_{\mathrm{OD}}=1-\frac{\mathrm{W}_{\mathrm{OD}}}{\mathrm{W}_{\mathrm{DP}}} \cdot\left(1-\mathrm{eff}_{\mathrm{DP}}\right)
$$

Basic sizing data is needed for the heat exchanger for modelling its transient operation and for evaluating its weight, namely the characteristic length, area, volume and mass. These values are calculated according to the simplified method described by Juhasz [42] and adopting the values suggested by the author, specifically: heat transfer coefficient equal to $142 \mathrm{~W} /\left(\mathrm{m}^{2} \mathrm{~K}\right)$, density equal to $3900 \mathrm{~kg} / \mathrm{m}^{3}$ and packing density of $3281 \mathrm{~m}^{2} / \mathrm{m}^{3}$. The heat exchanger pressure drop at design point is assumed $4 \%$ for the cold side and $5 \%$ for the hot side including the exit duct losses, in line with the values suggested in [20]. The effectiveness of the recuperator is expected to be in the range of 0.4 to 0.74 according to previous designs presented by McDonald et al [43].

A parametric analysis assuming design point effectiveness equal to $0.4,0.6$ and 0.8 is performed. The maximum continuous rating power (MCR) and max intermittent rating power ${ }^{2}$ of the recuperated engines are defined in accordance with the simple cycle engine T41 values. The simple cycle MCR and max intermittent rating are defined in accordance to the values presented in [44]. Having established the simple cycle power ratings the relevant T41values are established as presented in Figure 5. As seen in Figure 5 the imposed pressure losses by the recuperator have a detrimental effect on engine power. The overall performance for the two power ratings and for the recuperated and simple cycle engines is presented in Table 2.

\footnotetext{
2 Intermittent or Intermediate rating power of a helicopter engine is defined between one engine inoperative and maximum continuous.rating power typically time-limited to 30 or $60 \mathrm{~min}$.
} 
As seen the recuperated configurations have a max intermittent rating power decreased by approximately $200 \mathrm{~kW}$ compared to the simple cycle. The MCR power is decreased by more than $120 \mathrm{~kW}$ compared to the simple cycle engine. This means that these recuperated engines cannot be used on the same rotorcraft as the simple cycle engine. Hybrid propulsion systems may provide the additional power boost, negating this disadvantage. As expected, recuperation produces a significant betterment in terms of specific fuel consumption. The improvement is higher when the engine operates at part load as seen in Figure 6.

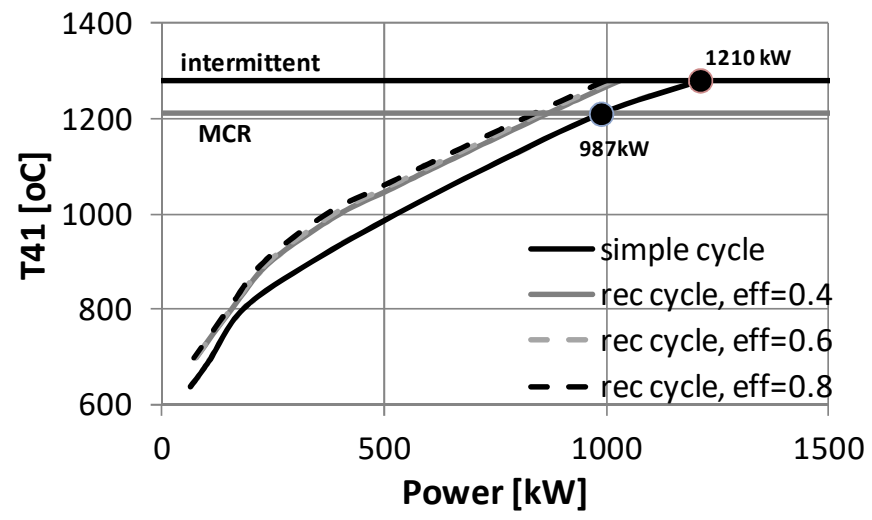

Figure 5: Turbine Inlet Temperature (T41) versus power for considered configurations

Table 2: Engine ratings for the configurations

\begin{tabular}{|c|c|c|c|c|}
\hline \multirow{2}{*}{ Case } & \multicolumn{2}{|c|}{ max inter rating } & \multicolumn{2}{c|}{ max cont rating } \\
\cline { 2 - 5 } & $\begin{array}{c}\mathbf{s f c} \\
{[\mathbf{g r} / \mathbf{k W h}]}\end{array}$ & $\begin{array}{c}\text { PGT } \\
{[\mathbf{k W}]}\end{array}$ & $\begin{array}{c}\text { sfc } \\
{[\mathbf{g r} / \mathbf{k W h}]}\end{array}$ & $\begin{array}{c}\mathbf{P G T} \\
{[\mathbf{k W}]}\end{array}$ \\
\hline open cycle & 285 & 1210 & 298 & 987 \\
\hline rec-eff=0.4 & 279 & 1031 & 285 & 868 \\
\hline rec-eff=0.6 & 258 & 1015 & 265 & 853 \\
\hline rec-eff=0.8 & 237 & 997 & 244 & 836 \\
\hline
\end{tabular}

The decrease of the recuperated engines sfc compared to the simple cycle sfc is depicted in Figure 7. Values of recuperation effectiveness in the range of $40-60 \%$ are considered plausible and in these cases a mean sfc reduction ranging from $10 \%$ to $15 \%$ can be expected. 


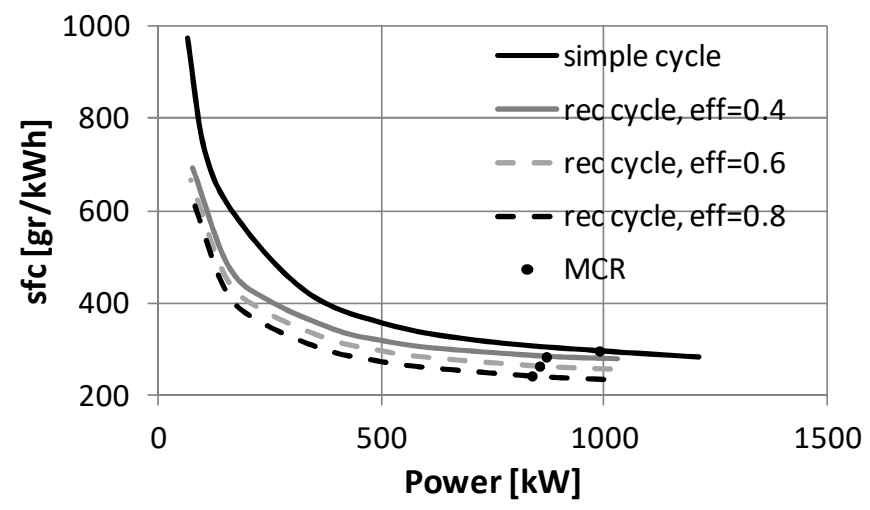

Figure 6: Specific fuel consumption versus power for considered configurations

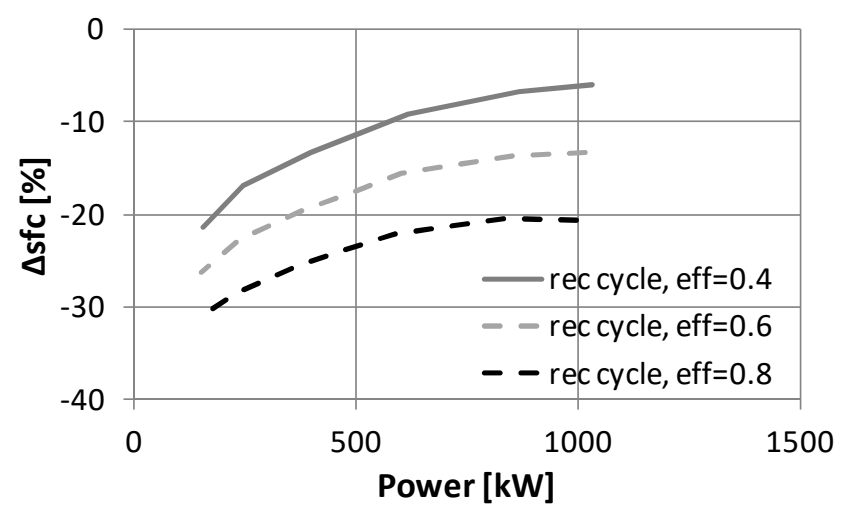

Figure 7: Recuperated engines sfc reduction compared to simple cycle engine

The dynamic behaviour of recuperated engines for rotorcraft propulsion has not been assessed despite the fact that the recuperator is expected to affect the operability and response of the engine [16]. As seen in Figure 8, the addition of the heat exchanger changes the response time of the gas turbine to external disturbances, as expected, due to the recuperator volume and thermal inertia. Higher effectiveness means larger volumes and masses resulting to longer engine reaction times. The change on the engine throttle behaviour may be addressed by suitable control system, since suitable over-fueling should be addressed or in the case of a hybrid system by utilizing the electric power train to provide the power reducing the lag.

This behaviour should be assessed when recuperated engines are considered, since there are specific manoeuvres that may be affected by an engine power lag. This lag is a strong function of thermal inertia, volumes and control system; hence for fully assessing recuperator effect on the overall engine transient operation more detailed heat exchanger design is needed along with a suitably design control system. 
Nevertheless, the recuperated model demonstrated a physically consistent behaviour and can be used for deriving general trends.

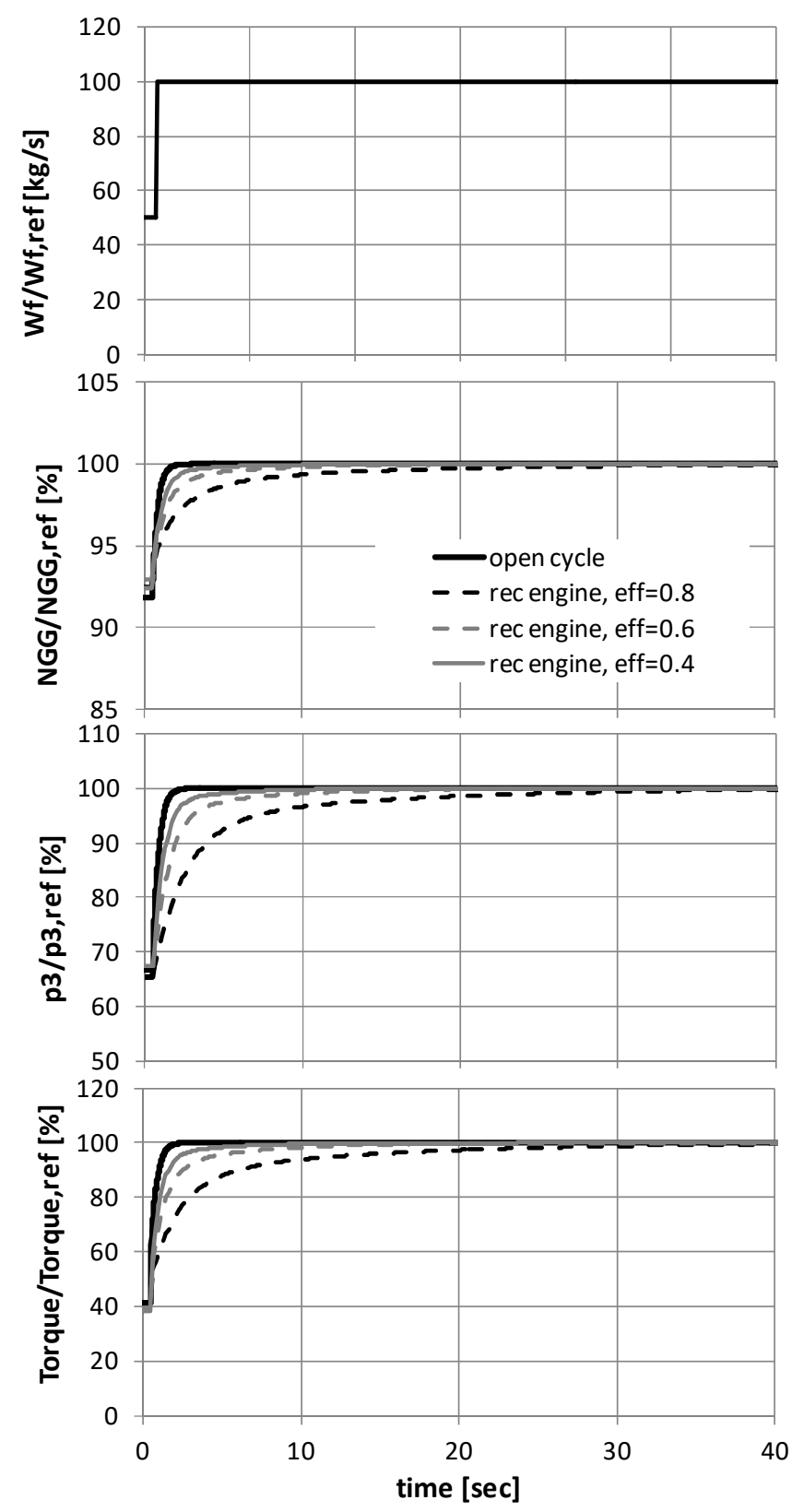

Figure 8: Simple cycle and recuperated configurations response to a fuel step increase

Recuperation increases the pressure ratio of the engine for a specific operating point due to the increased pressure losses; hence it is negatively affecting both compressors surge margin. This negative effect becomes more profound when transient operation is considered. The acceleration-deceleration manoeuvre depicted in Figure 9 
has a significant negative effect on surge margin for both engine compressors as depicted in Figure 10 and Figure 11. The effect of the heat exchanger thermal inertia on compressors operating line is significantly more profound than the effect of shaft inertia, moving the operating line towards surge and highlighting the importance of examining the engine operability along with the performance when new configurations or modifications that include heat exchangers are assessed.

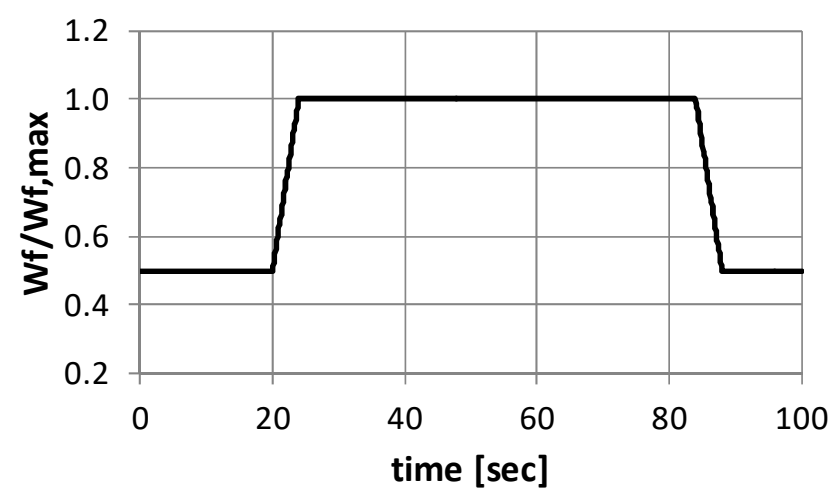

Figure 9: Imposed fuel increase relative to maximum

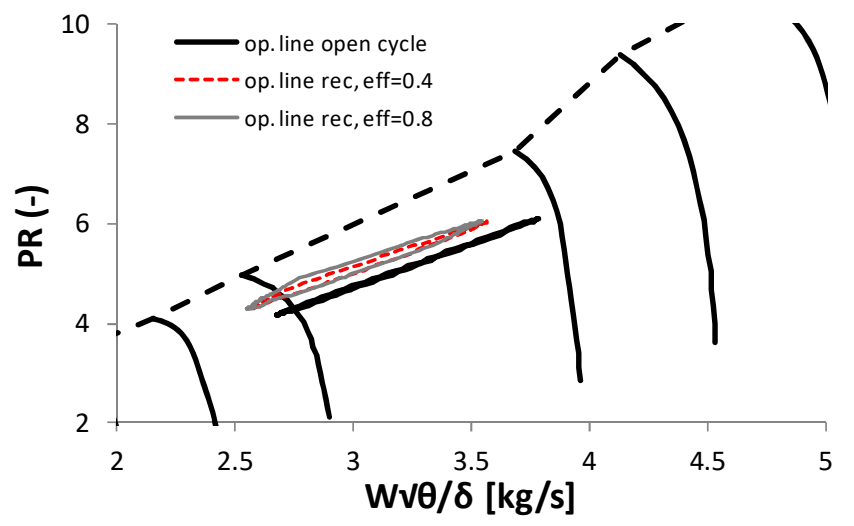

Figure 10: Simple cycle and recuperated engine response to the imposed fuel change axial compressor 


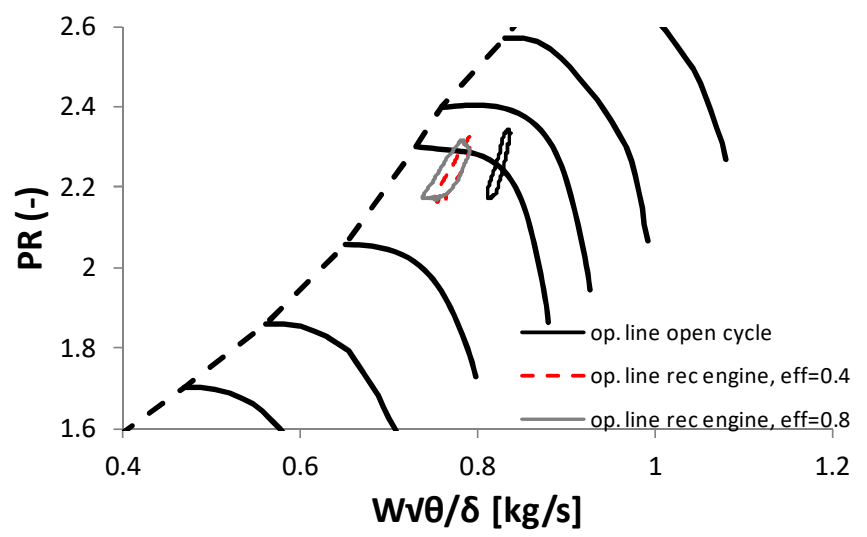

Figure 11: Simple cycle and recuperated engine response to the imposed fuel change centrifugal compressor

\section{PROPULSION SYSTEM WEIGHT ESTIMATION}

For assessing a hybrid propulsion configuration in terms of performance and fuel consumption the power train weight should be evaluated.

\section{Gas Turbine Weight Estimation}

The gas turbine engine may be sized down, given that the batteries can provide boosting power, or sized up if a single gas turbine configuration is selected. For accounting the engine scaling effect on the engine weight ATLAS, a Cranfield University in-house software [45] for engine sizing and preliminary structural assessment is used. ATLAS utilizes a component based approach in order to derive the overall "bare-engine" weight. Based on gas turbine theory fundamentals, it performs gas path designation and preliminary design for each of the main engine components.

Design considerations such as stage loading and de Haller number limitations, blockage factors, reaction targets and flow Mach numbers are included in order to determine the required technology level. Each engine component is accompanied by the rest of the parts necessary to complete a realistic engine module. The component designs combined with the appropriate gas turbine materials library are used for the engine weight estimation.

For the rotating discs, an approach similar to the one used in NASA WATE method is applied [46]. In this approach, the target is to find the minimum volume, and subsequently the minimum weight disk that satisfies the stress limitations imposed by 
its shape and its material. The main assumption here is that the disks are consisted by concentric rings while the calculation is performed based on the Sums \& Differences method [45]. The structural evaluation follows the Goodman approach.

The $2 \mathrm{D}$ engine cutaway generated by ATLAS for the test case engine utilizing the aerothermal data calculated by the model for the maximum intermittent rating is depicted in Figure 12 along with the original engine layout.

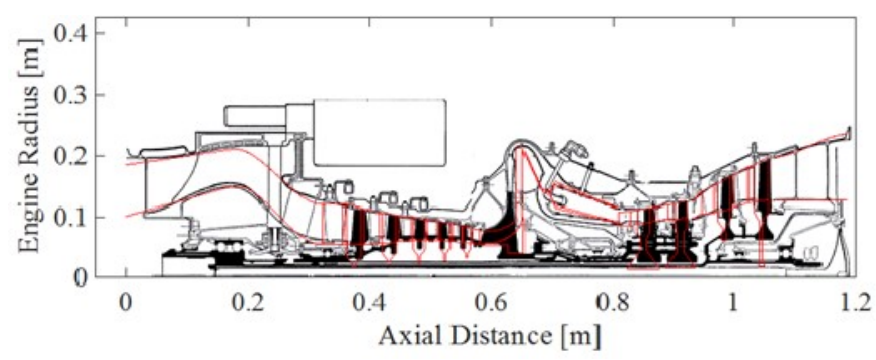

Figure 12: Engine cutaway comparison

The geometry obtained with ATLAS is comparable to the actual engine layout. The overall length and weight predicted by ATLAS for the test case engine are in good agreement with the actual length and weight reported in [44] (Table 3). Given that ATLAS can predict the engine weight utilizing performance data with acceptable accuracy; it is used herein to assess the engine weight change when engine scaling down is considered.

Table 3: Predicted and actual engine weight and length

\begin{tabular}{|c|c|c|c|}
\cline { 2 - 4 } \multicolumn{1}{c|}{} & ATLAS & DATA [44] & $\boldsymbol{\Delta}[\%]$ \\
\hline Weight $[\mathrm{kg}]$ & 186 & 198 & 5.9 \\
\hline Length $[\mathrm{m}]$ & 1.17 & 1.197 & 2.3 \\
\hline
\end{tabular}

\section{Electric Power Train Weight Estimation}

For evaluating the electric power train, the weight of each component should be calculated. The electric components weight is a strong function of the technology level. For the batteries, current state-of-the art Li-ion batteries have specific energy in the range of $200 \mathrm{Wh} / \mathrm{kg}$, while future developments are expected to increase this value to $2000 \mathrm{Wh} / \mathrm{kg}$ [47]. In order to estimate batteries weight, the overall amount of energy $\left(E_{\text {tot }}\right)$ is used, along with the energy density ( $\left.\rho_{\text {batt }}\right)$. Additionally a service factor $k_{\text {add }}$ equal 
to 1.3 is introduced, in order to take into account mass coming from harnesses and casing [48].

$$
M_{\text {batt }}[\mathrm{kg}]=\frac{E_{\text {tot }}[\mathrm{J}]}{\rho_{\text {batt }}[\mathrm{Wh} / \mathrm{kg}] \cdot 3600[\mathrm{~s} / \mathrm{h}]} \cdot \mathrm{k}_{\text {add }}
$$

The inverter aims at changing direct current into alternating current, or viceversa, depending on the application. Its mass can be related to the amount of power it has to handle, and can be computed knowing the power density ( $\rho_{\text {inv }}$ ). According to [49] a cable mass factor $k_{\text {cables }}$ equal to 1.2 is added to account for wires and electrical connections.

$$
M_{\text {inv }}[\mathrm{kg}]=\frac{P_{\text {inv }}[\mathrm{W}]}{\rho_{\text {inv }}[\mathrm{W} / \mathrm{kg}]} \cdot \mathrm{k}_{\text {cable }}
$$

Inverters usually suffer from low power density, but those based on SiC material can reach $7 \mathrm{~kW} / \mathrm{kg}$ [51]. The power density of the inverter is in the range of $2 \mathrm{~kW} / \mathrm{kg}$, while future values are expected to be as high as $16 \mathrm{~kW} / \mathrm{kg}$ [50]. Concerning the motors and generators the method adopted to compute the mass and the overall geometry is taken from [49] utilizing data from [52]. The design power along with the design and maximum rotational speed are inputs. The number of phases and poles, along with material components density are considered design variables. This input is used for calculating the electric machine components (stator, rotor, shaft and armature) sizes and weights. The overall mass is obtained summing the components weights. A service mass equal to $13 \%$ of the total is added to take into account the added weight of cables and mountings.

\section{THERMO-ELECTRIC POWERPLANT ASSESSMENT}

\section{Test Case Mission}

For assessing the thermo-electric powerplant a specific Twin Engine Medium helicopter and a representative Oil and Gas (OAG) mission are considered. HECTOR has been used for deriving the power demand for the specified mission. HECTOR is an inhouse rotorcraft comprehensive code [53] that has been used to reproduce with good accuracy power requirements for TEM helicopters [54], [55].

The OAG mission schedule assumes that the helicopter takes off from De Kooy Airfield in Den Helder, the Netherlands while carrying a specified payload. The 
helicopter subsequently travels towards a designated offshore oil/gas platform (oil rig 1) where it lands and drops off the on-board payload. The helicopter then travels towards a second offshore oil/gas platform (oil rig 2) where it picks up another useful payload and subsequently returns to the original De Kooy Airfield in Den Helder. Climb and descent rates are held fixed at $5 \mathrm{~m} / \mathrm{s}$ and $3.5 \mathrm{~m} / \mathrm{s}$, respectively. A time step of $5 \mathrm{~s}$ is used for each individual mission segment. All coordinated turns are executed with a turn rate of $5 \mathrm{deg} / \mathrm{s}$, with the exception of fine tuning of the helicopter's orientation, where the turn rate is defined based on the orientation error and the mission time step. The mission range is $206.8 \mathrm{~km}$ and the time is $4935 \mathrm{~s}$, the on-board payload is assumed equal to $616 \mathrm{~kg}$. The power demand for the mission, for TOW of $5760 \mathrm{~kg}$ is depicted in Figure 13.

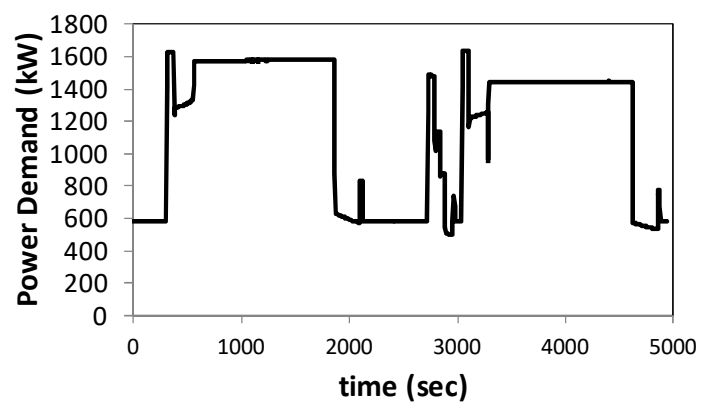

Figure 13: OAG mission total power demand (TOW $5760 \mathrm{~kg}$ )

\section{Propulsion System}

A parallel hybrid propulsion system for helicopters is examined herein with the partial electric drive of the main rotor supplementing the engine power. It is assumed that the twin-engine configuration is maintained, ensuring redundancy.

The propulsion system consists of two power sources, each consisting of a gas turbine mechanically connected to the motor through a gearbox that acts as a power splitter, while a battery provides power to the motor. The electric motor is used to assist the turboshaft engine when the power request is very high and for charging the battery when surplus of mechanical power is available and the battery stage of charge (SOC) is less than $30 \%$. A relevant model is built in Simcenter Amesim using the Aircraft Electrics and Electric Motor and Drives libraries (Figure 14). 
The battery, controller and motor design is done utilizing the Simcenter Amesim tools providing the voltage, energy and power demand for the battery and the power, the design and the maximum rotational speed for the motor and controller. The inverter efficiency is assumed constant and equal to 0.96 [50]. The motor design point efficiency is assumed equal to 0.94 [56], and changes at off-design operation. The torque demand is provided by the HECTOR. The gas turbine power throughout the mission is limited by the MCR turbine entry temperature (T41) as defined for the simple cycle. When the T41 becomes equal to the MCR T41, the fuel is stabilized and the battery is supporting the engine, providing the additional power, if needed.

Two configurations are assessed herein, one utilizing simple cycle engines as prime movers and one utilizing the recuperated engines:

a) For the simple cycle configuration the engine design point is scaled down from $100 \%$ to $60 \%$ of the baseline engine power. The scaling is done assuming the same cycle in terms of specific power and scaling the design inlet mass flow

b) For the recuperated configuration three cases assuming heat exchanger effectiveness $0.4,0.6$ and 0.8 are considered.

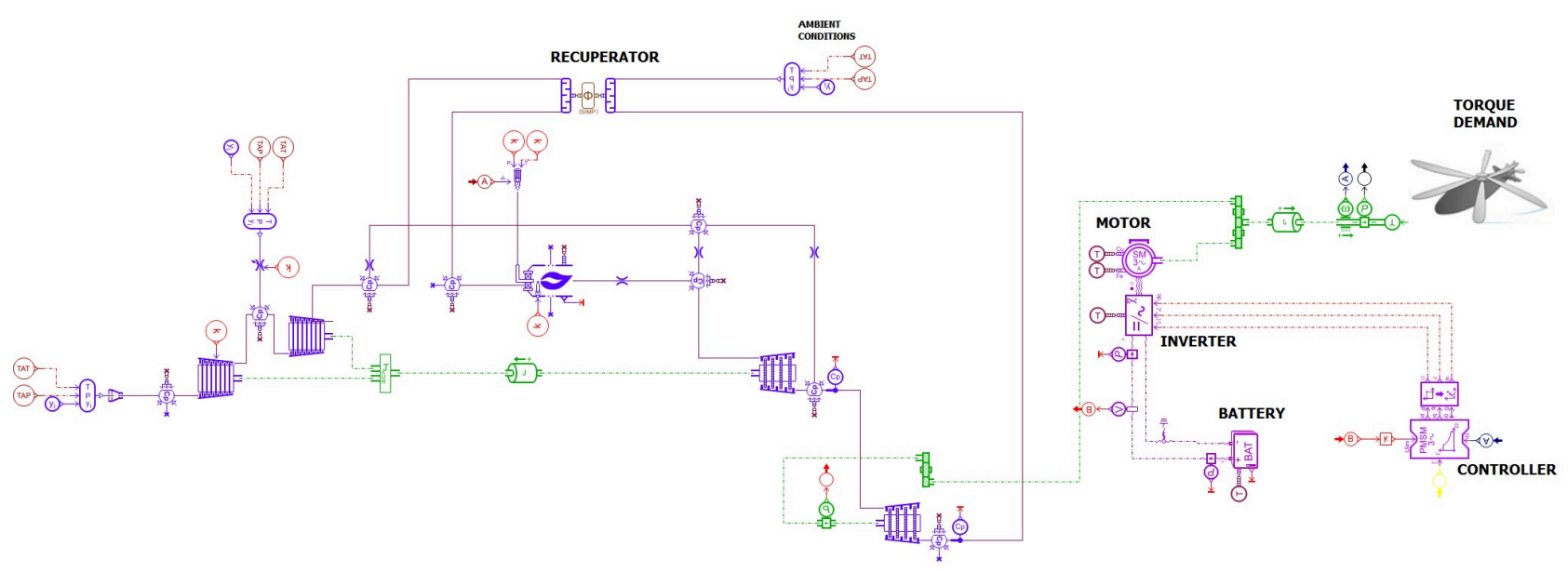

Figure 14: Parallel hybrid configuration for the recuperated engine

The OAG mission with a TOW of $5760 \mathrm{~kg}$ is defined as the test case mission, except if specifically stated otherwise. For each configuration, performance parameters such as the gas turbine overall mission efficiency, eq. (4), propulsion system overall efficiency, eq. (5), energy ratio, eq. (6) and the ratio of maximum electric power to 
propulsive power occurred during the flight, eq. (7) are calculated. Additionally a corrected system efficiency is introduced (eq. (8)) for taking into account that the electric energy production and its transfer to charging stations for charging the propulsion system batteries is not a $100 \%$ efficient process. The mission results (electric energy, maximum electric power and fuel consumption) are used for calculating the hybrid propulsion system overall weight. The effect of engine scaling to the engine weight and the weight of the heat exchanger as a function of effectiveness are also considered.

$$
\begin{aligned}
& \mathrm{GT}_{\mathrm{ov}, \mathrm{eff}}[\%]=\frac{\mathrm{GT} \text { Energy[kWh] }}{\text { Heat Input[kWh] }} \cdot 100 \\
& \text { Sys }_{\text {ov,eff }}[\%]=\frac{\text { Propulsive Energy[kWh] }}{\text { Heat Input }[k W h]+\text { Electric Energy[kWh] }} \cdot 100 \\
& E_{\text {RATIO }}(\%)=\frac{E_{\text {el }}[k W h]}{E_{\text {PROP }}[k W h]} \cdot 100 \\
& \mathrm{P}_{\text {RATIO }}(\%)=\left.\left(\frac{\mathrm{P}_{\mathrm{el}}[\mathrm{kW}]}{\mathrm{P}_{\text {prop }}[\mathrm{kW}]} \cdot 100\right)_{\max }\right|_{\mathrm{t}=0} ^{\mathrm{t}}
\end{aligned}
$$

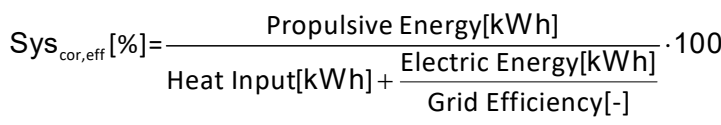

\section{Simple Cycle Configurations Assessment}

The energy split for the simple cycle engine configurations versus the engines design MCR is depicted in Figure 15. For this mission the engine has to be sized down to $80 \%$ of the baseline engine for the electric support to become necessary. This doesn't mean that an engine sized down to $90 \%$ of the baseline engine power will not need a power source for ensuring maximum intermittent and OEI capabilities. In the case of scaled down engines even if no electric power is used during the mission a hybrid system is still needed for the propulsion system to be capable to provide the maximum power ratings. As seen in Figure 16 the hybridization in terms of energy becomes significant when the engine is scaled down to the $70 \%$ of the baseline engine power. At the same time the maximum electric power to propulsive power ratio occurred during 
the mission is $9.5 \%$ for the engine scaled down to $80 \%$ of baseline power and it increases up to $36 \%$ for the engine scaled to $60 \%$ of the baseline engine.

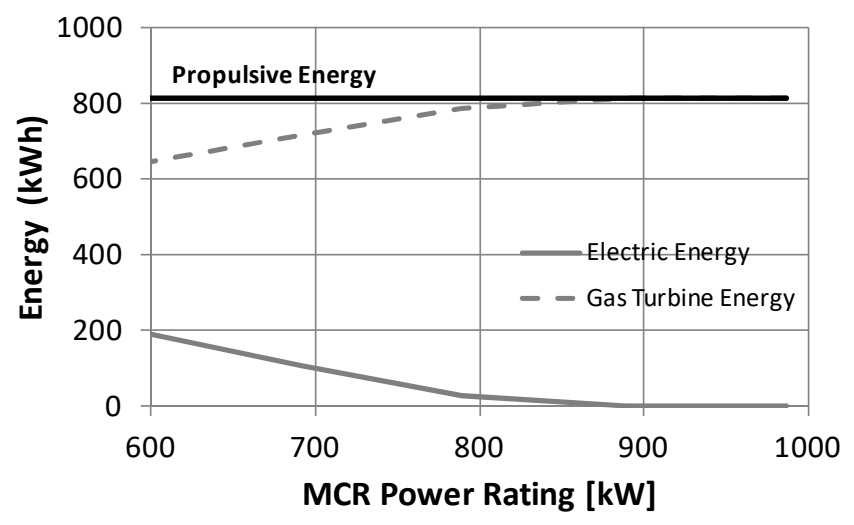

Figure 15: Energy split for the mission

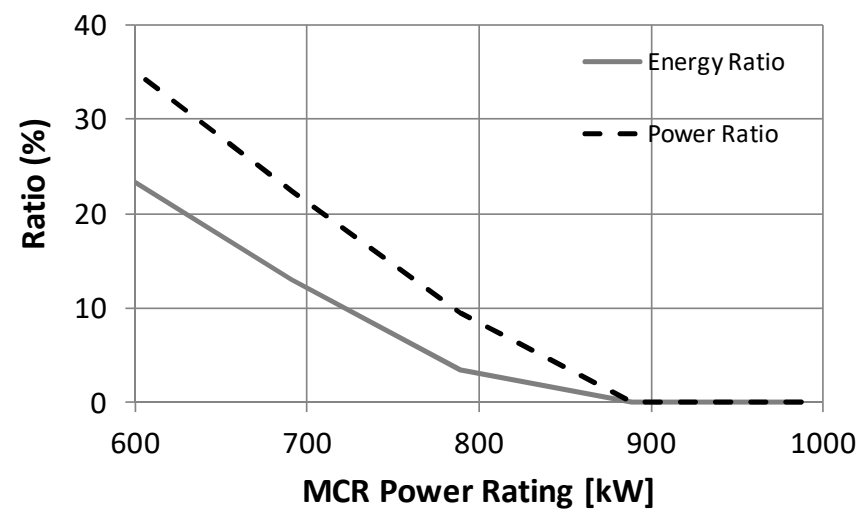

Figure 16: Overall energy and power ratio

The main benefit coming from the more electric concept is the engine working at more favourable operating points throughout the mission, as depicted in Figure 17. In this figure, the non-dimensional performance curve of the simple cycle engine is presented. The max intermittent power and sfc for each scaled down engine are used as reference values, accordingly. The power and sfc averaged over the whole mission for each scaled down engine are superimposed on the performance curve. As the engine is scaled down (increased hybridization) the "average" operating point is moving towards higher relative power, hence to lower sfc. 


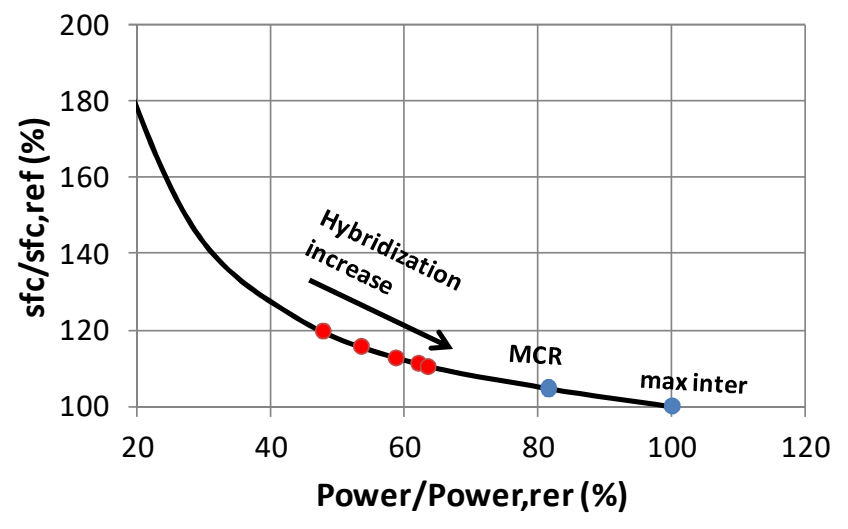

Figure 17: Mean operating points superimposed on engine performance curve

The gain due to operating point movement is expected to decrease as the engine is becoming smaller. This is due to the performance curve slope decreasing for higher power settings. This is evident when the gas turbine overall mission efficiency is examined. The gas turbine overall efficiency is saturated when the engine is scaled down to approximately $70 \%$ of the baseline engine power, as seen in Figure 18.

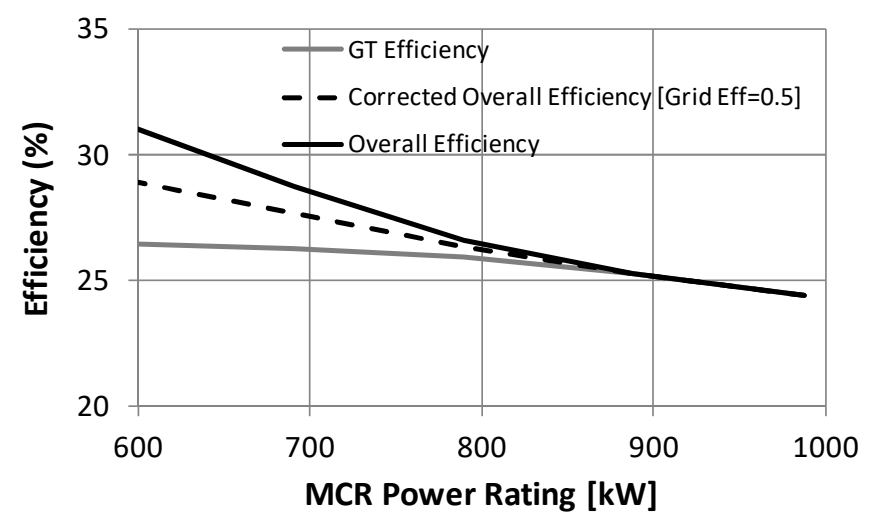

Figure 18: Propulsion system efficiencies

The overall efficiency is increasing given that the electric power is considered as input to the system with a mean efficiency of about $89 \%$ (motor and inverter efficiency). In reality, considering that the electric power may be for example produced from a Combined Cycle power plant, the efficiency conversion from fuel heat energy to electric energy would be in the range of 50 to $60 \%$. If this correction is employed the overall system efficiency gain due to hybridization is reduced considerably, as seen in Figure 18. This decrease highlights also the fact that utilizing in-flight charging will further compromise the overall hybrid system efficiency, since on top of the Brayton cycle 
inefficiencies the electric power train inefficiencies would be applied twice. On the other hand in-flight charging may be necessary for reducing batteries weight and for increasing safety.

Having established the electric energy needed the electric power and the engine power the overall propulsion system weight can be calculated utilizing the methods described. The batteries power density is assumed $200 \mathrm{Wh} / \mathrm{kg}$ and the controller power density $7 \mathrm{~kW} / \mathrm{kg}$. It should be highlighted that the electric motor and controller are sized so the propulsion system can provide the baseline engine high power ratings. The battery for the engine scaled to $90 \%$ of baseline engine power is sized as to ensure maximum power availability for $2.5 \mathrm{~min}$. The batteries mission energy demand is increased by a safety factor of 1.2. The relevant data is presented in Table 4 . As seen the weight increases significant as the hybridization increases, making the configurations utilizing gas turbines scaled down to $70 \%$ and $60 \%$ of the baseline engine power very heavy.

Table 4: Simple cycle propulsion system weight per engine

\begin{tabular}{|c|c|c|c|c|c|c|c|c|}
\hline $\begin{array}{c}\text { MCR } \\
\text { Power }\end{array}$ & $\begin{array}{c}\text { El. Energy } \\
\text { mission }\end{array}$ & $\begin{array}{c}\text { Pel,max } \\
\text { mission }\end{array}$ & $\begin{array}{c}\text { Engine } \\
\text { Weight }\end{array}$ & $\begin{array}{c}\text { Block } \\
\text { Fuel }\end{array}$ & $\begin{array}{c}\text { Motor } \\
\text { Weight }\end{array}$ & $\begin{array}{c}\text { Battery } \\
\text { Weight }\end{array}$ & $\begin{array}{c}\text { Controller } \\
\text { Weight }\end{array}$ & $\Delta$ weight \\
\hline$[\mathrm{kW}]$ & {$[\mathrm{kWh}]$} & {$[\mathrm{kW}]$} & {$[\mathrm{kg}]$} & {$[\mathrm{kg}]$} & {$[\mathrm{kg}]$} & {$[\mathrm{kg}]$} & {$[\mathrm{kg}]$} & {$[\mathrm{kg}]$} \\
\hline 987 & 0 & 0 & 186 & 278 & 0 & 0 & 0 & 0 \\
\hline 888 & 0 & 0 & 169 & 268 & 23 & 33 & 22 & 52 \\
\hline 790 & 28 & 75 & 153 & 253 & 46 & 220 & 45 & 252 \\
\hline 691 & 106 & 177 & 138 & 227 & 70 & 827 & 67 & 866 \\
\hline 592 & 197 & 285 & 125 & 201 & 93 & 1535 & 90 & 1580 \\
\hline
\end{tabular}

\section{Recuperated Cycle Configurations Assessment}

For the recuperated cycle configurations the hybridization is rather small, as seen in Figure 19. The hybridization increases with recuperator effectiveness due to the MCR decreasing. 


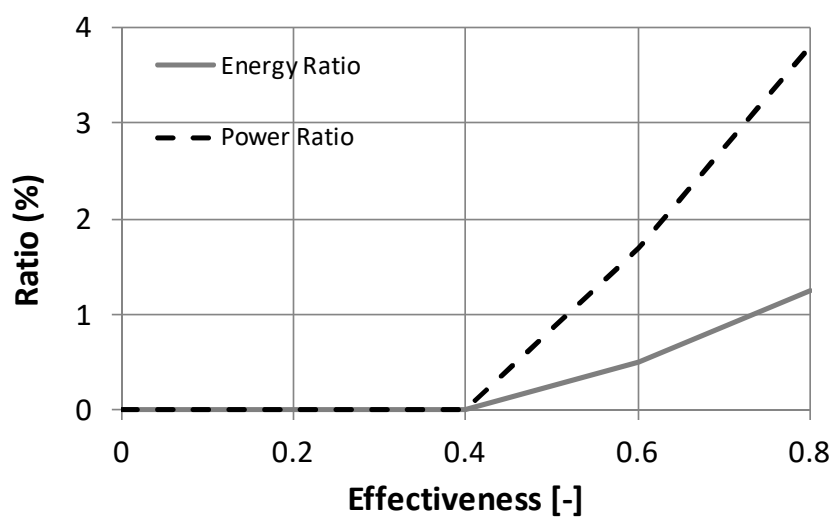

Figure 19: Overall energy and power ratio

Given that the electric power is providing power at short intervals throughout the mission the dominant efficiency is the gas turbine efficiency, as seen in Figure 20. The gas turbine efficiency is rather high, despite the fact that the engines are not scaled down. The efficiency increase comes with the penalty of the heat exchanger (HX) weight. Additionally the electric power train is sized for providing the power and energy for ensuring high power ratings capability. The relevant weights are presented in Table 5. It is apparent that high effectiveness means better fuel economy. This betterment comes with the price of higher weight, longer acceleration times and reduced surge margin.

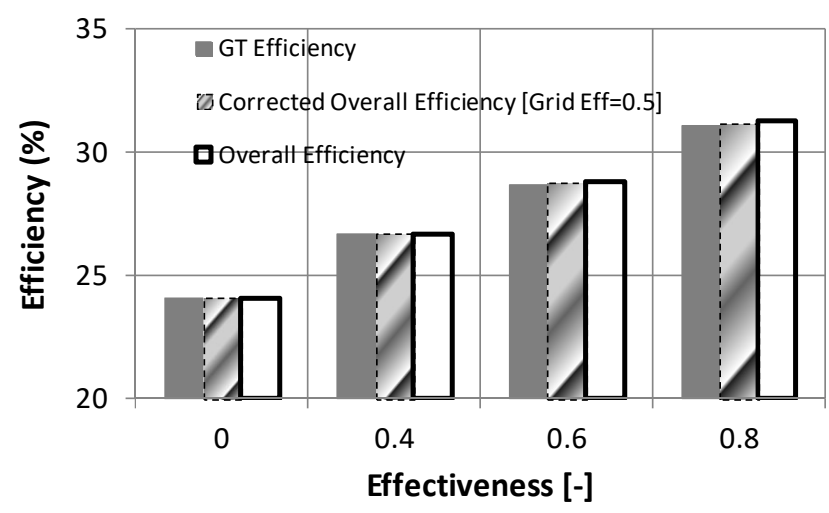

Figure 20: Propulsion system efficiencies 


\section{Table 5: Recuperated cycle propulsion systems weight}

\begin{tabular}{|c|c|c|c|c|c|c|c|c|c|}
\hline $\begin{array}{c}\text { MCR } \\
\text { Power }\end{array}$ & $\begin{array}{c}\text { Electric } \\
\text { Energy }\end{array}$ & $\begin{array}{c}\text { Pel, max } \\
\text { mission }\end{array}$ & $\begin{array}{c}\text { Engine } \\
\text { Weight }\end{array}$ & $\begin{array}{c}\mathrm{HX} \\
\text { Weight }\end{array}$ & $\begin{array}{c}\text { Block } \\
\text { Fuel }\end{array}$ & $\begin{array}{c}\text { Motor } \\
\text { Weight }\end{array}$ & $\begin{array}{c}\text { Battery } \\
\text { Weight }\end{array}$ & $\begin{array}{c}\text { Controller } \\
\text { Weight }\end{array}$ & $\Delta$ weight \\
\hline$[\mathrm{kW}]$ & {$[\mathrm{kWh}]$} & {$[\mathrm{kW}]$} & {$[\mathrm{kg}]$} & {$[\mathrm{kg}]$} & {$[\mathrm{kg}]$} & {$[\mathrm{kg}]$} & {$[\mathrm{kg}]$} & {$[\mathrm{kg}]$} & {$[\mathrm{kg}]$} \\
\hline 987 & 0 & 0 & 186 & 0 & 278 & 0 & 0 & 0 & 0 \\
\hline 868 & 0 & 0 & 186 & 32 & 251 & 34 & 39 & 33 & 111 \\
\hline 850 & 4 & 13 & 186 & 69 & 232 & 37 & 52 & 36 & 149 \\
\hline 835 & 10 & 30 & 186 & 176 & 213 & 41 & 79 & 40 & 271 \\
\hline
\end{tabular}

As seen in Figure 21 the energy reduction achieved with the recuperated hybrid configurations is more significant compared to the simple cycle hybrid configurations for the same weight addition, even when low values of recuperator effectiveness is considered. The energy decrease per unit of added mass achieved for the recuperated configuration is five times greater compared to the simple cycle configuration.

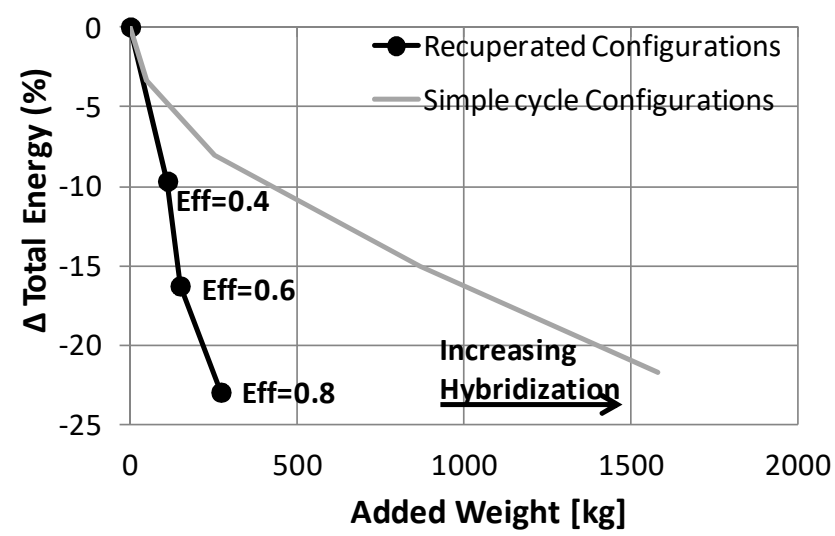

Figure 21: Energy consumption decrease vs added weight

For further assessing the overall performance effect of hybridization the mission block fuel is calculated taking into consideration the increased weight of the helicopter for each configuration, as calculated. In this case the reference test case is the conventional simple cycle propulsion system for the OAG mission for TOW equal to $5000 \mathrm{~kg}$. For the hybrid configurations the batteries are fully charged at the end of the mission. For the simple cycle hybrid configuration only the cases of a scaled down engine to $90 \%$ and $80 \%$ are considered since as seen in Figure 21 further increasing hybridization decrease the energy reduction per added weight. It is apparent that when the additional weight is considered the potential benefit is reduced but nevertheless the improvement is significant. As seen in Figure 22 the recuperated configurations give a significant gain in terms of block fuel despite the added weight. The betterment is in the range of $10 \%$ for a recuperator effectiveness of $40 \%$ and $18 \%$ for $80 \%$ effectiveness. 
These values indicate that hybrid propulsion may be an enabling technology for recuperated cycles. The simple cycle configurations on the other hand give a marginal improvement that reduces as hybridization increases. The increase of the propulsion system weight is going to decrease the helicopter payload. If an increase in maximum TOW is selected for maintaining the maximum payload then a heavier rotor would be required. The cases of interest in this study, depicted in Figure 22 correspond to a weight increase from $4 \%$ to $10 \%$.

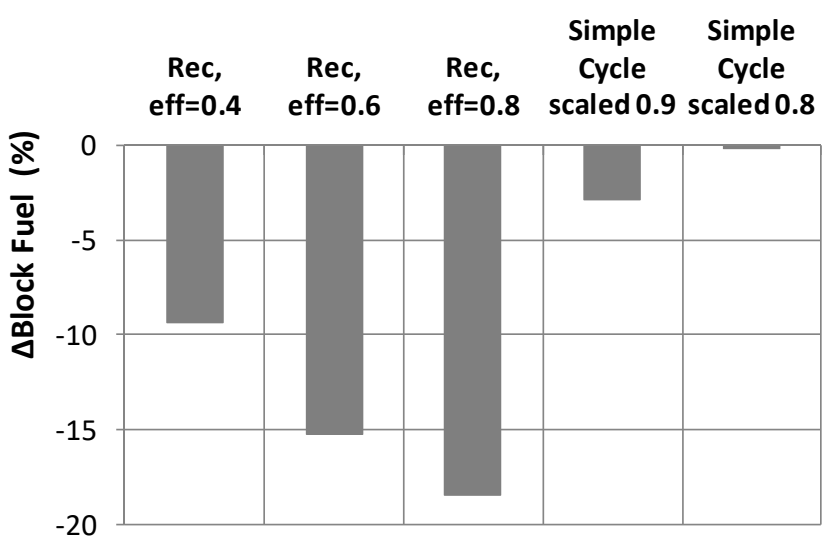

Figure 22: Block fuel reduction compared to conventional configuration, accounting for hybrid system weight

Another interesting aspect of hybridization is the utilization of the electric system as a buffer when transients are considered, especially for the recuperated cycles. As seen in Figure 23 the integrated hybrid system utilizing the recuperated cycle demonstrates a rather fast throttle response since the time constants of the electrical system are rather small compared to the gas turbine [17].

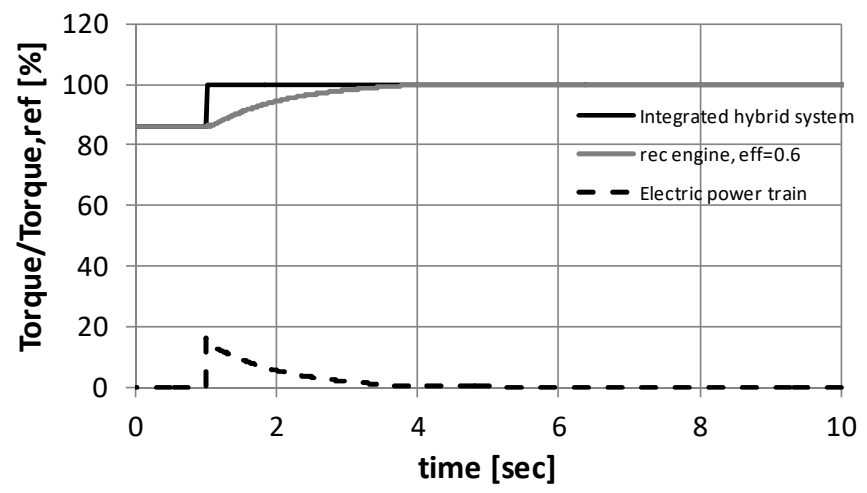

Figure 23: Throttle response of the integrated hybrid system and its power components: the recuperated gas turbine and the electric power train 
In this case (Figure 23) despite the throttle delay of the gas turbine, the electric power train provides the additional power to the system for the short period needed. It should be noted that gearbox inertia and potential control system lag are not considered. Additionally aspects such as circuit protection to accommodate transients should be considered as discussed in [57].

\section{SUMMARY AND CONCLUSIONS}

A parallel hybrid propulsion system utilizing simple and recuperated cycle gas turbine configurations is assessed. Firstly, a fully adapted engine model capable to reproduce an engine steady state and transient operation is built and used as a baseline for the recuperated engine. The results indicate that the model built in Simcenter Amesim has been adapted with good accuracy to the relevant steady state data and presents the expected behaviour in terms of time constants and values when transient operation is considered.

Following a recuperated version of the simple cycle engine is built and simulated for heat exchanger effectiveness ranging from 0.4 to 0.8 . The expected behaviour is observed namely recuperation produces a significant betterment in terms of specific fuel consumption, especially for part load operations. Values of recuperation effectiveness in the range of $40-60 \%$, which are considered plausible, may produce a mean sfc reduction ranging from $10 \%$ to $15 \%$ for the complete operating envelope. During transient manoeuvres the recuperated engine is lagging compared to the simple cycle due to the recuperator thermal inertia. The lagging becomes greater as the effectiveness increases. This behaviour should be assessed when recuperated engines are considered, since there are specific manoeuvres that may be affected by engine throttle lag. The addition of a heat exchanger has a detrimental effect on surge margin as well. The surge margin reduction during transient becomes more significant as the effectiveness and size of the heat exchanger increases.

Having established a recuperated version of the engine a parallel hybrid configuration utilizing both the simple cycle and the recuperated configuration models is built in Simcenter Amesim. An OAG mission of a representative twin engine medium 
helicopter is used as a test case. The propulsion system weight is calculated according to the electric energy and power, the heat exchanger effectiveness and the high power ratings demand of the engine (max intermittent and OEI).

Firstly, the performance of simple cycle gas turbine based configurations is assessed. The engines are scaled down versions of the baseline engine; hence they operate to operating points of low sfc. The propulsion system efficiency increases significantly, but so does the weight. The results indicate that the weight increases significant when hybridization values of more than $8 \%$ are considered. The energy reduction per unit of added mass is reduced as the hybridization level increases, suggesting that when current technologies are considered the hybridization level should be low.

The recuperated engine based thermo-electric power plant designed has low hybridization values, since the electric power train is mostly used to compensate for the reduced specific power due to the heat exchanger addition. Despite the additional weight the recuperated engine with an effectiveness of 0.4 may provide a fuel decrease over the OAG mission of about $9 \%$. This value may increase up to $19 \%$ when effectiveness of 0.8 is considered. The integrated hybrid configuration can also negate the effect of lagging of the recuperated engine, since the electric power train can rapidly provide torque during the system transients.

The energy consumption reduction per unit of added weight achieved through the mission for the recuperated engine configurations is 5 times larger compared to the simple cycle configuration values, indicating that recuperated cycles are rather appealing to be used as prime movers for thermo-electric propulsion systems.

Additionally, since the recuperated engine models are based on an existing simple cycle engine the results indicate that hybridization may support the introduction of recuperated engines in rotorcraft propulsion utilizing existing engine designs reducing the development time and cost. 


\begin{tabular}{|c|c|}
\hline \multicolumn{2}{|c|}{ NOMENCLATURE } \\
\hline \multicolumn{2}{|c|}{ ABBREVIATIONS } \\
\hline BOV & Blow-Off Valve \\
\hline$C T$ & Core Turbine \\
\hline$G T$ & Gas Turbine \\
\hline HPC & High Pressure Compressor \\
\hline LPC & Low Pressure Compressor \\
\hline $\mathrm{MCR}$ & Maximum Continuous Rating \\
\hline PGT & Power of Gas Turbine \\
\hline$P R$ & Pressure Ratio \\
\hline PT & Power Turbine \\
\hline sfc & Specific Fuel Consumption \\
\hline SOC & State of Charge \\
\hline TOW & Take-Off Weight \\
\hline VGV & Variable Guide Vanes \\
\hline \multicolumn{2}{|c|}{ SYMBOLS } \\
\hline$E$ & Energy \\
\hline eff & Effectiveness \\
\hline eta & Efficiency \\
\hline$M$ & Mass \\
\hline$N G G$ & Gas Generator Relative Rotational Speed \\
\hline$N p$ & Power Turbine Relative Rotational Speed \\
\hline$p$ & Pressure \\
\hline$P$ & Power \\
\hline$T$ & Temperature \\
\hline$W$ & Air Mass Flow \\
\hline$W f$ & Fuel Mass Flow \\
\hline \multicolumn{2}{|c|}{ SUBSCRIPTS } \\
\hline$D P$ & Design Point \\
\hline$O D$ & Off-Design \\
\hline 2 & Compressor Inlet Station \\
\hline 3 & Compressor Outlet Station \\
\hline 41 & Turbine Rotor Inlet Station \\
\hline \multicolumn{2}{|c|}{ GREEK SYMBOLS } \\
\hline$\delta$ & $\mathrm{p}_{2} /$ preference \\
\hline$\vartheta$ & $\mathrm{T}_{2} / \mathrm{T}_{\text {reference }}$ \\
\hline
\end{tabular}




\section{REFERENCES}

[1] Airbus, 2016, "Global Market Forecast, Mapping Demand 2016/2035," Technical report

[2] D'Ippolito, R., Stevens, J., Pachidis, V., Berta, A., Goulos, I., and Rizzi, C., 2009, “A Multidisciplinary Simulation Framework for Optimization of Rotorcraft Operations and Environmental Impact," 2nd International Conference on Engineering Optimization (EngOpt 2010), Lisbon, Portugal, September, 2010, pp. 6-9

[3] Smith C., Pachidis V., Castillo Pardo A., Gires E., Stevens J., Thevenot L., d'Ippolito R., "Achieving Rotorcraft noise and Rmissions Reduction for 'Clean Sky' - The Measurement of Success" 5th CEAS Air \& Space Conference-Challenges in European Aerospace. 7-11 September 2015, Delft, Netherlands

[4] Clarke, J.-P., 2003, "The role of advanced air traffic management in reducing the impact of aircraft noise and enabling aviation growth", Journal of Air Transport Management, 9(3), pp. 161-165

[5] Kirner R., Raffaelli L., Rolt A., Laskaridis P., Doulgeris G. \& Singh R. (2015) An assessment of distributed propulsion: Advanced propulsion system architectures for conventional aircraft configurations, Aerospace Science and Technology, 46, pp. 42-50

[6] Kyprianidis G. K., Grönstedt T., Ogaji S. O. T., Pilidis P. Singh R., 2010, “Assessment of Future Aero-engine Designs With Intercooled and Intercooled Recuperated Cores", J. Eng. Gas Turbines Power 133(1), 011701 (10 pages)

[7] Voskuijl, M., van Bogaert, J. and Rao, A. G. (2017) 'Analysis and Design of Hybrid Electric Regional Turboprop Aircraft', CEAS Aeronautical Journal. Springer Vienna, 9(1), pp. 15-25. doi: 10.1007/s13272-017-0272-1

[8] Bradley M, Droney C, Paisley D, Roth B, Gowda S, Kirby M., 2010, "NASA N+3 Subsonic Ultra Green Aircraft Research SUGAR Final Review", Boeing Research and Technology

[9] Vratny C. P., Forsbach F., Seitz A., Hornung M., 2014, “Investigation of Universally Electric Propulsion Systems for Transport Aircraft", 29th Congress of the International Council of the Aeronautical Sciences at: St. Petersburg, Russia

[10] Kailos N. C., "Increased helicopter capability through advanced power plant technology", Journal of the American Helicopter Society, 12(3) ,pp. 1-15

[11] Privoznik, E. J., 1968, "Allison T63 Regenerative Engine Program”, Journal of the American Helicopter Society, 13(4), pp. 56-63 
[12] Colin F. McDonald, Aristide F. Massardo, Colin Rodgers, Aubrey Stone, 2008 "Recuperated gas turbine aeroengines, part II:engine design studies following early development testing", Aircraft Engineering and Aerospace Technology, 80(3), pp.280294

[13] Lei Xu, Konstantinos G. Kyprianidis, and Tomas U. J. Grönstedt, 2013, "Optimization Study of an Intercooled Recuperated Aero-Engine", Journal of Propulsion and Power, 29(2) pp. 424-432.

[14] Fakhre A., Goulos I, Pachidis V, 2015, "An Integrated Methodology to Assess the Operational and Environmental Performance of a Conceptual Regenerative Helicopter", Aeronautical Journal, 119, pp. 1-24.

[15] Roumeliotis I., Nikolaidis T., Pachidis V., Broca O., Unlu D., 2018, "Dynamic Simulation of a Rotorcraft Hybrid Engine in Amesim", 44th European Rotorcraft Forum, Delft, The Netherlands, 19-20 September, 2018

[16] Colin F. McDonald, Aristide F. Massardo, Colin Rodgers, Aubrey Stone, 2008 "Recuperated Gas Turbine Aeroengines. Part III: Engine Concepts for Reduced Emissions, Lower Fuel Consumption, and Noise Abatement", Aircraft Engineering and Aerospace Technology, 80(4), pp.408-426

[17] Wortmann G, Schmitz O and Hornung M., 2014, "Comparative assessment of transient characteristics of conventional and hybrid turbine engine", CEAS Aeronaut Journal, 5, pp. 209-223

[18] Vratny P. C., Kaiser S., Seitz A., Donnerhack S., 2017, "Performance Investigation of Cycle- Integrated Parallel Hybrid Turboshafts", ASME Journal of Engineering for Gas Turbines and Power, 139(3) (9 pages)

[19] Ballin M. G, 1988, "A High Fidelity Real-Time Simulation of a Small Turboshaft Engine", Technical report, NASA Ames Research Center

[20] Walsh, P.P. and Fletcher, P., 2004, Gas Turbine Performance, 2nd Edition, Blackwell Science, Oxford

[21] Kurzke J., 2007, "About Simplifications in Gas Turbine Performance Calculations", ASME paper No. GT2007-27620

[22] AGARD-AR-332, 1995, "Recommended Practices for the Assessment of the Effects of Atmospheric Water Ingestion on the Performance and Operability of Gas Turbine Engines", North Atlantic Treaty Organization.

[23] Stamatis, A., Mathioudakis, K., Smith, M., Papailiou, K.D., "Gas Turbine Component Fault Identification by Means of Adaptive Performance Modelling". ASME Paper 90-GT376, 1990 
[24] Basendwah A. A., Pilidis P., Li Y. G., "Turbine Off- Line Water Wash Optimization Approach for Power Generation”, ASME paper No. GT2006-90244

[25] A.H. Lefebvre and D.R. Ballal, 2010, "Gas Turbine Combustion, Alternative Fuels and Emissions", 3rd Ed., Taylor and Francis Group, LLC

[26] McBride J. B., Zehe J. M., Gordon S., 2002, "NASA Glenn Coefficients for Calculating Thermodynamic Properties of Individual Species". NASA/TP-2002-211556

[27] International Organization for Standardization, 1975, "Standard Atmosphere", ISO 2533:1975

[28] U.S. Standard Atmosphere, 1976, NASA-TM-X-74335

[29] MIL-STD-3013, 2013, "Glossary of Definitions, Ground Rules, and Mission Profiles to Define Air Vehicle Performance Capability"

[30] MIL-HDBK-310, 1997, “Military Handbook: Global climatic Data for Developing Military Products"

[31] Brenan K.E., Campbell S.L., Petzold L.R., 1989, "Numerical Solution of Initial-Value problems in Differential-Algebraic Equations", North-Holland

[32] Lapidus L., Seinfeld J,. 1971, “Numerical Solution of Ordinary Differential Equations, Academic Press",

[33] Petzold L. R., 1983, "Automatic Selection of Methods for Solving Stiff and Nonstiff Systems of Ordinary Differential Equations", SIAM J. Sci. and Stat. Comput., 4(1), 136148

[34] Roumeliotis I.; Aretakis N.; Mathioudakis K., 2003, "Performance Analysis of TwinSpool Water Injected Gas Turbines Using Adaptive Modelling", ASME paper No. GT200338516

[35] Roumeliotis I., Aretakis N., Alexiou A., 2017, "Industrial Gas Turbine Health and Performance Assessment with Field Data", ASME J. Eng. Gas Turbines Power 139(5), 10 pages

[36] Nkoi B., Pilidis P., Nikolaidis T., 2013, "Performance assessment of simple and modified cycle turboshaft gas turbines", Propulsion and Power Research, 2(2), pp. 96106 
[37] Pachidis, V., The Turbomatch scheme; for aero/industrial gas turbine engine design point/off design performance calculation, Manual, Cranfield University, UK, October 1999

[38] Gunston B. Jane's Aero-Engines. 1996. General Electric Aircraft Engine Business Group. Model Specication for T700-GE-700 Turboshaft Engine, Part I. Technical report, 1983

[39] Kurzke, J., 2002, 'Performance Modelling Methodology: Efficiency Definitions for Cooled Single and Multistage Turbines', ASME paper No. GT-2002-30497

[40] Horobin, M. S., 1999, "Cycle-Match Engine Models used in Functional Engine Design - An Overview", RTO Meeting Proceedings: MP-8 Design Principles and Methods for Aircraft Gas Turbine Engines, pp. 44.1-44.22

[41] Maria V. C., Garcia Rosa, N., Carbonneau X., 2016, "Sensitivity Analysis and Experimental Validation of Transient Performance Predictions for a Short-Range Turbofan", ASME paper No. GT2016-57257

[42] Juhasz A. J., 2010, "A Mass Computation Model for Lightweight Brayton Cycle Regenerator Heat Exchangers", NASA/TM-2010-216799, 8th International Energy Conversion Engineering Conference (IECEC) sponsored by the American Institute of Aeronautics and Astronautics Nashville, Tennessee, July 25-28, 2010

[43] Colin F. McDonald, Aristide F. Massardo, Colin Rodgers, Aubrey Stone, 2008, "Recuperated gas turbine aeroengines, part I: early development activities", Aircraft Engineering and Aerospace Technology, Vol. 80 Issue: 2, pp.139-157

[44] Ed. Gunston B., 2004, "Jane's Aero-Engines", Issue Fifteen - March 2004, Jane's Information Group Limited

[45] Lolis, P., 2014, “Development of a Novel Preliminary Aero Engine Weight Estimation Method", PhD Thesis, Propulsion Engineering Centre, Cranfield University

[46] Pera, R. J., Onat, E., Klees, G. W., Tjonneland, E., 1977, "A method to estimate weight and dimensions of aircraft gas turbine engines" Volume 1: Method of analysis final report, Technical Report NASA-CR-135170, NASA

[47] Bruce G. P., Freunberger A. S., Hardwick J. L, Tarascon J., 2011, "Li-O2 and Li-S batteries with high energy storage", Nature Materials

[48] Vratny C. P., Pornet C., Isikveren T. A., Hornung M., 2013, "Battery Pack Modelling Methods for Universally-Electric Aircraft", 4th CEAS Air and Space Conference, Wien 
[49] Vratny C. P., Forsbach P., Seitz A., Hornung M., 2014, "Investigation of Universally Electric Propulsion Systems for Transport Aircraft", 29th Congress of the International Council of the Aeronautical Sciences, San Petersburg

[50] Brown V. G., 2011, "Weights and Efficiencies of Electric Components of a Turboelectric Aircraft Propulsion System", NASA, 49th AIAA Aerospace Sciences Meeting, Orlando

[51] Brombach J., Schröter T., Lucken A., Schulz D., 2012, "Optimizing the Weight of an Aircraft Power Supply System through a +/- 270 VDC Main Voltage", Przeglad Elektrotechniczny, Helmut-Schmidt-University, Airbus Operations GmbH

[52] Jonathan E. Rucker, 2012, "Design and Analysis of a Permanent Magnet Generator for Naval Applications", MSc Thesis, MIT

[53] Goulos I., 2012, "Simulation Framework Development for the Multidisciplinary Optimization of Rotorcraft", Ph.D. Thesis, Cranfield University, Cranfield

[54] Carretero J. O., Pardo C. A., Goulos I., Pachidis V., 2018, "Impact of Adverse Environmental Conditions on Rotorcraft Operational Performance and Pollutant Emissions", ASME Journal of Engineering for Gas Turbines and Power, 140(2), 13 pages

[55] Goulos I., Giannakakis P., Pachidis V., Pilidis P., 2013, “Mission Performance Simulation of Integrated Helicopter-Engine Systems Using an Aeroelastic Rotor Model", J. Eng. Gas Turbines Power 135(9)

[56] Robert A. McDonald. 2014, "Electric Propulsion Modeling for Conceptual Aircraft Design", 52nd Aerospace Sciences Meeting, AIAA SciTech Forum, AIAA paper No. 20140536

[57] National Academies of Sciences, Engineering, and Medicine. 2016. Commercial Aircraft Propulsion and Energy Systems Research: Reducing Global Carbon Emissions. Washington, DC: The National Academies Press. https://doi.org/10.17226/23490. 
2019-10-01

\section{Assessment of thermo-electric power plants for rotorcraft application}

Roumeliotis, loannis

ASME

Roumeliotis I, Mourouzidis C, Zafferetti M, et al., (2020) Assessment of thermo-electric power plants for rotorcraft application. Journal of Engineering for Gas Turbines and Power, Volume 142, Issue 5, May 2020, Article number 051003, Paper number GTP-19-1402 https://doi.org/10.1115/1.4045103

Downloaded from Cranfield Library Services E-Repository 